\title{
Prophylactic intracameral vancomycin: efficacy in preventing endophthalmitis after cataract surgery
}

\author{
Manash Kumar Goswami, Md. Ferdous Hossain and Md. Asaduzzaman \\ Department of Ophthalmology, Bangladesh Institute of Research and Rehabilitation in Diabetes, \\ Endocrine and Metabolic Disorder (BIRDEM), Dhaka
}

\begin{abstract}
Background and objective: Post Operative endophthalmitis is rare but devastating complication in ocular surgery. The present study determined the efficacy of intracameral vancomycin after phaco-emusification cataract surgery to prevent endophthalmitis.

Method: A total of 768 cases who had undergone phaco-emusification cataract surgery were included in the study. Every alternate patient received $0.5 \mathrm{ml}$ injection of vancomycin (1mg in $0.1 \mathrm{ml}$ ) in the anterior chamber after completion of phaco-emulcification and formation of anterior chamber. All the patients were examined for symptoms and signs of bacterial endophthalmitis at 24 hrs, 7 days, 15 days and subsequently at 1, 3 and 6 months following surgery.

Results: No endophthalmitis case was recorded at any time period during 6 month follow up in either group. However, significantly higher number of cases in vancomycin group had cells in anterior chamber and disturbances in visual acuity at day 15 following surgery.
\end{abstract}

Conclusion: Vancomycin did not have any prophylactic role in preventing endophthalmitis. Proper aseptic measures are important to prevent any infection in ocular surgery.

IMC J Med Sci 2016; 10(1): 24-28

\section{Introduction}

Intraocular infection following cataract surgery and lens implantation is a rare but dreadful complication that can have devastating consequences for sight. The Endophthalmitis Vitrectomy Study (EVS) estimated that up to half of patients developing endophthalmitis following cataract surgery had visual acuity worse than $20 / 40$ and $15 \%$ had worse than $5 / 200$ [1]. The incidence of endophthalmitis following cataract surgery varies between 0.04 and $0.27 \%$ [2-4]. Even though several risk factors have been identified, this complication is often unexpected, with variable response to standard treatment. The number of cataract surgeries is expected to rise with an increasing aging population in Bangladesh; the burden of endophthalmitis is likely to rise. A robust preventative strategy is needed to contain this serious complication. The European Society of Cataract and Refractive Surgeons (ESCRS) in a multinational, partially-masked placebo-controlled trial have provided strong evidence for using intracameral antibiotics in preventing postoperative endophthalmitis following cataract surgery [5]. In this study, we determined the prophylactic effect of vancomycin injection in the anterior chamber at the end of phacoemulsification surgery in preventing post operative bacterial endophthalmitis.

\section{Methods}

A total of 768 cases undergoing phacoemulsification cataract surgery from January 2014 to December 2015 in the Department of Ophthalmology at BIRDEM general hospital were enrolled in the study. Every alternate eye (patient) received

\section{Address for Correspondence:}

Dr. Manash Kumar Goswami, Associate Professor, Department of Ophthalmology, BIRDEM General Hospital, 122 Kazi Nazrul Islam Avenue, Shahbag, Dhaka. Email: manashkg@yahoo.com 
intracameral injection of vancomycin (vancomycin group) while others did not receive any intracameral antibiotic and served as a control. The cases in control arm were treated according to the exiting protocol followed in the hospital for cataract surgery as described below.

In the anesthetic room, 10 minutes prior to cataract surgery, each patient had periocular skin cleaning with $5 \%$ povidone iodine. Two drops of $5 \%$ povidone iodine were instilled into the conjunctival sac at this stage. The surgeon, after scrubbing and draping, used $5 \%$ povidone iodine to cleanse the eyelids and periocular skin. The eyelids including the eye lashes were draped. All cataract surgeries were performed in a dedicated ophthalmic theatre assisted by resident doctor and ophthalmic specialist nurses. Phacoemulsification was performed using infiniti machine (Alcon). Every alternate patient got $0.5 \mathrm{ml}$ injection of vancomycin $(1 \mathrm{mg}$ in $0.1 \mathrm{ml}$ ) in the anterior chamber of the eye after completion of phaco-emulcification and formation of anterior chamber [5]. Postoperatively, patients were prescribed prednisolone acetate $1 \%$ eye drop twohourly for two weeks which was then tapered off over a further four weeks. In addition, all cases received topical moxifloxacin eye drop two hourly for 1 week and 6 hourly for 2 weeks. All the patients were examined for symptoms and signs of bacterial endophthalmitis [4] at 24 hrs, 7days, and 15 days and subsequently at 1,3 and 6 months following surgery.

The study was approved by the IRB of BADAS and informed written consent was obtained from each patient.

\section{Results}

A total of 768 cases were enrolled in the study of which 384 were in vancomycin group and 384 were in control group. The age range of the study population was 45-80 years. Male female distribution in vancomycin group was 283 and 101 respectively while in control group it was 237 and 147. All had type 2 diabetes mellitus of various durations. During the follow up, visual acuity, conjunctival congestion, cells in the anterior chamber and features of endophthalmitis were recorded. Table 1 shows the results of follow up at $24 \mathrm{hrs}, 15$ day and 6 month. Lost to follow up at day 15 and at 6 month were 44 and 23 cases in control group; 10 and 15 cases in vancomycin group respectively. No patients in any group developed features of bacterial endophthalmitis during this period. At $24 \mathrm{hrs}$, significantly higher proportion of cases had cells in anterior chamber in vancomycin group compared to control $(22.3 \%$ vs $9.3 \% ; \mathrm{p}<0.05)$. Visual acuity was significantly $(\mathrm{p}<0.05)$ poor in vancomycin group $(20.6 \%)$ compared to control $(8.3 \%)$ at 15 day follow up. However, the visual acuity was similar in both groups at 6 month.

Table-1: Results of follow up of study population at $24 \mathrm{hrs}, 15$ day and 6 month following phacoemulsification cataract surgery

\begin{tabular}{|c|c|c|}
\hline Parameters & $\begin{array}{c}\text { Without } \\
\text { vancomycin } \\
\text { (Control) } \\
\text { N (\%) } \\
\end{array}$ & $\begin{array}{c}\text { With } \\
\text { vancomycin } \\
\mathbf{N}(\%)\end{array}$ \\
\hline \multicolumn{3}{|l|}{ At $24 \mathrm{hrs}$} \\
\hline Number of cases (n) & 384 & 384 \\
\hline Visual acuity & & \\
\hline $6 / 6-6 / 9$ & $201(52.3)$ & $187(48.6)$ \\
\hline $6 / 12-6 / 24$ & $105(27.3)$ & $151(39.3)$ \\
\hline 6/36-above & $78(20.3)$ & $46(11.9)$ \\
\hline Conjunctival congestion & $67(17.4)$ & $78(20.3)$ \\
\hline $\mathrm{A} / \mathrm{C}$ cells ++ & $36(9.3)$ & $86(22.3)$ \\
\hline Endophthalmitis & 0 & 0 \\
\hline \multicolumn{3}{|l|}{ At 15 day } \\
\hline Number of cases & 340 & 374 \\
\hline Drop out & 44 & 10 \\
\hline \multicolumn{3}{|l|}{ Visual acuity } \\
\hline $6 / 6-6 / 9$ & $308(90.6)$ & $297(79.4)$ \\
\hline $6 / 12-6 / 24$ & $25(7.4)$ & $47(12.6)$ \\
\hline 6/36-above & $7(2.1)$ & $30(8.0)$ \\
\hline Endophthalmitis & 0 & 0 \\
\hline \multicolumn{3}{|l|}{ At 6 month } \\
\hline Number of case & 361 & 369 \\
\hline Drop out & 23 & 15 \\
\hline Visual acuity & & \\
\hline $6 / 6-6 / 9$ & $318(88.1)$ & $315(85.4)$ \\
\hline $6 / 12-6 / 24$ & $37(10.2)$ & $49(13.3)$ \\
\hline 6/36-above & $6(1.7)$ & $5(1.4)$ \\
\hline Endophthalmitis & 0 & 0 \\
\hline
\end{tabular}

Note: $A / C$ : anterior chamber; $p<0.05$ when compared between vancomycin and control group for visual acuity at day 15. 
Discussion

Anterior segment intraocular surgery frequently introduces bacteria into the anterior chamber [6]. In $65 \%$ to $100 \%$ of healthy subjects, conjunctiva and adnexa were found to be colonized by microorganisms with the potential to cause endophthalmitis [7, 8]. In $82 \%$ of cases of endophthalmitis, the organism isolated was the same species as that found in the conjunctiva and lids of the same patient [9]. In the 420 cases of endophthalmitis in the EVS series, $70 \%$ of the isolates were coagulase negative staphylococci.

Prophylactic measures to reduce postoperative endophthalmitis after cataract surgery are wide and varied. Several perioperative and postoperative methods have been recognized. Preoperative iodine antisepsis combined with preoperative and postoperative topical antibiotic therapy is considered the standard of care for this purpose [10]. In the last decade intracameral administration of antibiotics has evolved as a prophylactic to prevent postoperative endophthalmitis after cataract surgery, claiming superior effectiveness compared with standard care. Intracameral antibiotics can achieve high concentrations in the anterior chamber but have the potential to cause corneal endothelial toxicity [11]. However, cefuroxime and vancomycin have been reported safe on human corneal endothelial cells in clinically used concentration, but at higher concentrations it could cause irreversible cell death.

The choice of intracameral antibiotic prophylaxis appears to be empirical, based on the fact that the majority of isolates are Gram-positive organisms. The first report of intracameral antibiotic prophylaxis with gentamicin was by Peyman et al [12]. Later, Gimbel et al [13] reported no case of endophthalmitis in a series of 12,000 patients after using an infusion fluid of gentamicin together with vancomycin during cataract surgery. The choice of prophylactic antibiotics included cefuroxime, cefazolin and vancomycin based on the pattern of organisms, antibiotic resistance profile, cost and possible adverse effects [14-19].

In our study, we serially enrolled 384 patients undergoing phacoemulsification cataract surgery at BIRDEM general hospital over two year's period. Meticulous aseptic technique was followed in the operation theater. In the present series there was no single case of endophthalmitis in either group. However, cells in the anterior chamber immediately following surgery was significantly higher in vancomycin group compared to control who did not receive vancomycin. Similarly, the visual acuity was significantly poor in vancomycin group at 15 day follow up. But the visual acuity in vancomycin group gradually improved over time and was same as the control at 6 month. The reduced visual acuity observed among the patients in both group could be due to the presence of other co-morbid conditions like diabetes, aging, hypertension, etc. Though minimal, patient should be monitored if vancomycin is used as prophylactic antibiotic in cataract surgery. There was no adverse effect like cystoid macular edema in intracameral vancomycin group. Significant increase in incidence of cystoid macular edema has been reported with the use of intracameral vancomycin during extracapsular cataract extraction [20]. It is interesting to note that no endophthalmitis has occurred in our cases who did not receive vancomycin as prophylaxis indicating that proper aseptic technique was adequate alone to prevent endophthalmitis and other infections following eye surgery. A recent survey on antibiotic prophylaxis practice after cataract surgery in the UK has reported that $37 \%$ of the respondents did not use intracameral antibiotic prophylaxis [21].

The present study demonstrated that proper pre and per operative aseptic measures together with the post operative use of standard topical antibiotics is adequate to prevent the bacterial endophthalmitis in cataract surgery. Routine use of prophylactic intracameral vancomycin did not have any additive value for the prevention of post operative bacterial endophthalmitis.

\section{References}

1. Endophthalmitis Vitrectomy Study Group. Results of the Endophthalmitis Vitrectomy Study: A randomized trial of immediate vitrectomy and of intravenous antibiotics for the treatment of postoperative bacterial endophthalmitis. Arch Ophthalmol 1995; 113: 1479-1496. [PubMed] 
2. Taban M, Beherens A, Newcomb RL, et al. Acute endophthalmitis following cataract surgery: A systematic review of the literature. Arch Ophthalmol 2005; 123: 613620. [PubMed]

3. Hatch WV, Cernat G, Wong D, Devenyi R, Bell CM. Risk factors for acute endophthalmitis after cataract surgery: A population-based study. Ophthalmology 2009; 116: 425-430. [PubMed]

4. Miller JJ, Scott IU, Flynn HW, Jr, Smiddy WE, Newton J, Miller D. Acute onset endophthalmitis after cataract surgery (20002004): Incidence, clinical settings, and visual acuity outcomes after treatment. $\mathrm{Am} J$ Ophthalmol 2005; 139: 983-987. [PubMed]

5. Barry P, Seal DV, Gettinby G, Lees F, Peterson M, Revie CW. ESCRS study of prophylaxis of postoperative endophthalmitis after cataract surgery: Preliminary report of principal results from a European multicenter study; the ESCRS Endophthalmitis Study Group. J Cataract Refract Surg 2006; 32: 407410. [PubMed]

6. Dickey JB, Thompson KD, Jay WN. Anterior chamber aspirate cultures after uncomplicated cataract surgery. Am J Ophthalmol 1991; 112: 278-282. [PubMed]

7. Speaker MG, Milch FA, Shah MK, Eisner W, Kreiswirth BN. Role of external bacterial flora in the pathogenesis of acute postoperative endophthalmitis. Ophthalmology 1991; 98: 639-649. [PubMed]

8. Boes DA, Lindquist TD, Firtsche TR, Kalima RE. Effects of povidone iodine chemical preparation and saline irrigation on the perlimbal flora. Ophthalmology 1992; 99: 1569-1573. [PubMed]

9. Bannerman TL, Rhoden DL, McAllister SK, Miller JM, Wilson LA. The source of coagulase-negative staphylococci in the Endophthalmitis Vitrectomy Study: A comparison of eyelid and intraocular isolates using pulsed-field gel electrophoresis: The Endophthalmitis Vitrectomy Study Group. Arch Ophthalmol 1997; 115: 357361. [PubMed]
10. Ciulla TA, Starr MB, Masket S. Bacterial endophthalmitis prophylaxis for cataract surgery: An evidence-based update. Ophthalmology 2002: 10913-10924. [PubMed]

11. Yoeruek E, Spitzer MS, Saygili O, et al. Comparison of in vitro safety profiles of vancomycin and cefuroxime on human corneal endothelial cells for intracameral use. $J$ Cataract Refract Surg 2008; 34: 21392145. [PubMed]

12. Peyman GA, Sathar MI, May DR. Intraocular gentamicin as intraoperative prophylaxis in South India eye camps. Br J Ophthalmol 1977; 61: 260-262. [PMC free article] [PubMed]

13. Gimbel HV, Sun R, DeBroff BM. Prophylactic intracameral antibiotics during cataract surgery: The incidence of endophthalmitis and corneal endothelial cell loss. Eur J Implant Refract Surg 1994; 6: 280-285.

14. Garat M, Moser CL, Alonso-Tarres C, Martin-Baranera M, Alberdi A. Intracameral cefazolin to prevent endophthalmitis in cataract surgery: 3-year retrospective study. J Cataract Refract Surg 2005; 31: 2230-2234. [PubMed]

15. Montan PG, Wejde G, Setterquist H, Rylander M, Zetterstom C. Prophylactic intracameral cefuroxime: Evaluation of safety and kinetics in cataract surgery. J Cataract Refract Surg 2002; 28: 982-987. [PubMed]

16. Hospital Infection Control Practices Advisory Committee (HICAC) Recommendations for preventing the spread of vancomycin resistance. Infect Control Hosp Epidemiol 1995; 16: 105-113. [PubMed]

17. Garat $\mathrm{M}$, Moser CL, Alonso-Tarres C, Martin-Baranera M, Alonso-Tarres C, Alvarez-Rubio L. Prophylactic intracameral cefazolin after cataract surgery: Endophthalmitis risk reduction and safety results in a 6-year study. $J$ Cataract Refract Surg 2009; 35: 637-642. [PubMed]

18. Montan PG, Wejde G, Koranyi G, Rylander M. Prophylactic intracameral cefuroxime: efficacy in preventing endophthalmitis after cataract surgery. J Cataract Refract Surg 2002; 28: 977-981. [PubMed] 
19. Seal DV, Barry P, Gettinby G, et al. ESCRS study of prophylaxis of postoperative endophthalmitis after cataract surgery: Case for a European multicenter study; the ESCRS Endophthalmitis Study Group. $J$ Cataract Refract Surg 2006; 32: 396-406. [PubMed]

20. Axer-Siegel R, Stiebel-Kalish H, Rosenblatt I, Strassmann E, Yassur Y, Weinberger D.
Cystoid macular edema after cataract surgery with intraocular vancomycin. Ophthalmology 1999; 106(9): 1660-1664. [PubMed]

21. Gore DM, Angunawela RI, Little BC. United Kingdom survey of antibiotic prophylaxis practice after publication of the ESCRS Endophthalmitis Study. J Cataract Refract Surg 2009; 35: 770-773. [PubMed] 